\title{
THE DEVELOPMENT OF MAGNETIC GEARS FOR TRANSPORTATION APPLICATIONS
}

\author{
Slavica Miladinović ${ }^{1}$, Lozica Ivanović ${ }^{2}$, Mirko Blagojević ${ }^{3}$, Blaža Stojanović ${ }^{4}$
}

UDC: 629.3.032.2;621.8.038

\section{INTRODUCTION}

The power transmission is mechanical in most machines, and it is commonly achieved in the use of gear transmissions. Mechanical gear transmissions have a high torque density, but the friction occurs in them, which is often the cause of the gear failure. Also, the noise, heat and vibration are present, so the reliability of these gears is reduced.

Nowadays, it is more and more taken care of the energy conservation, and therefore the environment as well, when designing new products. The goal is to reduce the noise, vibration, to simplify maintenance more, reduce heat and reduce dimensions. The magnetic gears are the new type of gears, which attract the attention of the constructors because of the possibility to overcome some of these problems. These are non-contact gears, where the power and torque transmission is achieved with the help of magnetic forces. Friction, wear and fatigue are not present in magnetic gears, they do not require lubrication, and they can be applied as a protective mechanism against overloading. They can operate in a wide temperature range, from $-270^{\circ} \mathrm{C}$ to $350^{\circ} \mathrm{C}$. Also, the operation is reversible, so the same device, in which they are installed, can be used as a reducer and as a multiplier.

The concept of magnetic gear was proposed about a hundred years ago. Their main advantage, in comparison to the conventional gears, the lack of contact and wear of teeth, was the reason enough for the further development of magnetic gears. However, the low efficiency, complex structure and high costs of their making, represented a significant problem. The production of magnetic gears for general industrial applications was enabled with the development of new magnetic materials of high magnetic permeability, the new precise production techniques and advanced modelling tools. Thus, the number of researchers interested in the development of structural solutions and performances of magnetic gears has grown. Historical overview of magnetic gears, as well as achievements accomplished in this area, has been presented in the literature [1]. There are a large number of papers on the topic of magnetic gears. Figure 1 shows the number of papers published from 1900 to 2015, obtained from the literature [1,2] and the available data on published papers.

\footnotetext{
${ }^{1}$ Slavica Miladinović, Ph. D. student, University of Kragujevac, Faculty of Engineering, Sestre Janjić

6, Kragujevac, slavicam@kg.ac.rs

${ }^{2}$ Lozica Ivanović, Prof., University of Kragujevac, Faculty of Engineering, Sestre Janjić 6,

Kragujevac,lozica@kg.ac.rs

${ }^{3}$ Mirko Blagojević, Prof., University of Kragujevac, Faculty of Engineering, Sestre Janjić 6,

Kragujevac,mirkob@kg.ac.rs

4 Blaža Stojanović, Prof., University of Kragujevac, Faculty of Engineering, Sestre Janjić 6 ,

Kragujevac,blaza@kg,ac.rs
} 


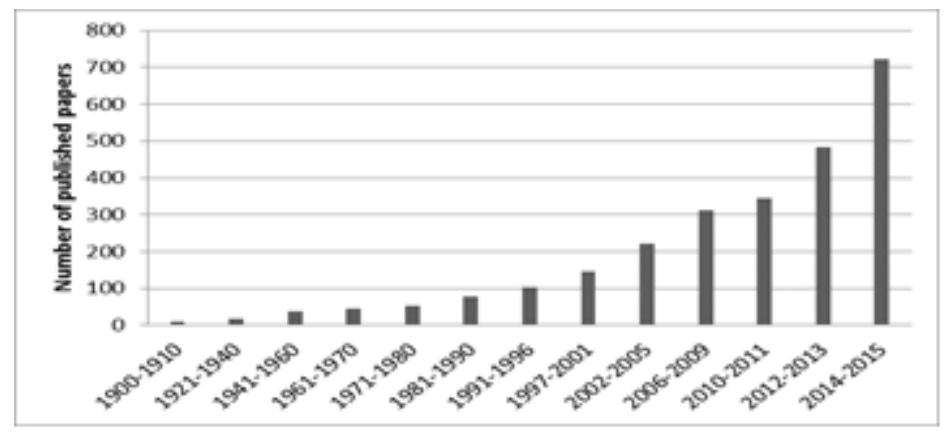

Figure 1 Statistics of published works

The number of papers dedicated to magnetic gears has increased exponentially over the last two decades, and the development of technology has allowed us to overcome many of the first problems.

\section{STATE OF THE ART OF MAGNETIC TRANSMISSION}

Different types of gears are used in industry for power and torque transmission. The gears with which the power transmission is realized by meshing of the gear teeth are called mechanical gears. The first such gears appeared more BC. Today, mechanical gears have a very broad application. The main advantages of these gears are that they are easy to make and that they have high efficiency, but disadvantages include high noise, friction, maintenance costs, vibration and heating.

With the development of technology, the aim is to develop other ways of power and torque transmissions, whereby the noise, vibration, maintenance costs, etc. would be lower. One of those ways is the use of magnets in the power transmission.

The magnet, as the power transmission device, was suggested for the first time by Armstrong C. G. in 1901 in his patent number 687292 [3]. The power transmission principle in magnetic gear devices is similar as with mechanical ones, except that the gear is not made with teeth meshing but without the contact, by applying magnetic force. Magnetic forces are obtained by the current flowing through the coil windings that are placed on the driving gear teeth. In addition to magnetic gears, whose gears rather resemble conventional cylindrical gears (figure 2) [4], there are concepts of magnetic gears resembling mechanical planetary gears. Magnetic planetary gears were first introduced in the patent from 1916 [5]. At the end of the 20th century, Ackerman had patented its magnetic planetary gear solution given in [6]. 


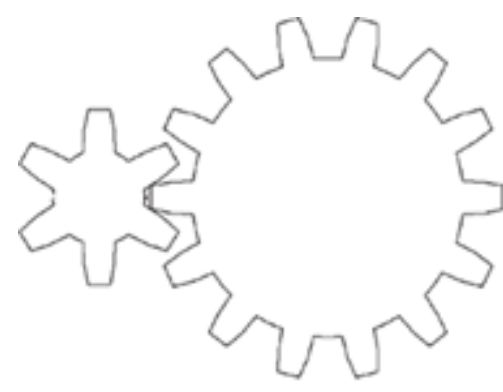

a)

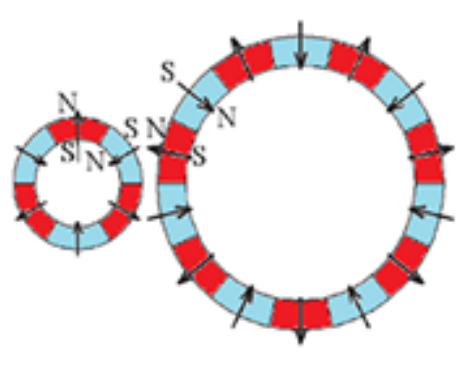

b)

Figure 2 a) Mechanical spur gear and b)Permanent-magnet gear [4]

There are many more patents on the topic of magnetic gears. Among them, there is a patent of cylindrical magnetic gears, published by Hetzel in 1974 [7], as well as the planetary gear patented by Mabe in 1991 [8]. Kikuchi \& Tsurumoto experimented in 1993 with magnetic worm gears [9], and Yao et al. conceived the magnetic bevel gears in 1996 [10].

It is known that the realization of magnetic gears is ascribed to the implementation of a permanent magnet that can produce permanent flux and magnetic field, which makes it possible to achieve non-contact torque transmission. The ferrite was used in the beginning as the material for permanent magnets, and its good properties are low cost and easy production, while its disadvantages are low magnetic induction and transmission of low torque. With appearance of the new material neodymium-iron-boron $(\mathrm{NdFeB})$, who had much better characteristics than ferrite, the magnetic gears came again into the limelight of the scientists in 1980s and their development was intensified.

The advantages of magnetic gears enabled the diversity of their practical application. The examples of these gears in hybrid vehicles are given in $[11,12,13]$. The Magnomatics Company developed a combination of motor and gear, which was named Pseudo Direct Drive, as well as MAGSPLIT, which was applied in hybrid vehicles [14].

\section{TYPES OF MAGNETIC GEARS}

Magnetic gears are divided into two types, as following: converted and magnetic gears with variable magnetic field.

Converted magnetic gears, which are also called the magnetic gears with direct effect, by its shape are reminiscent of the mechanical ones, except that instead of teeth they have magnets. Many magnetic gears can be classified in this group, and some of them are: magnetic worm gear, magnetic rack and pinion, magnetic bevel gear and magnetic spur gear (external and internal). Figure 3 shows a comparative view of magnetic and mechanical gears. 


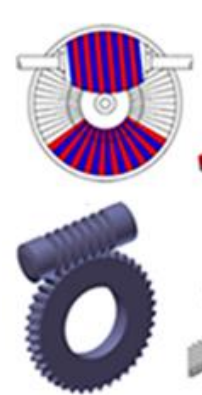

a)
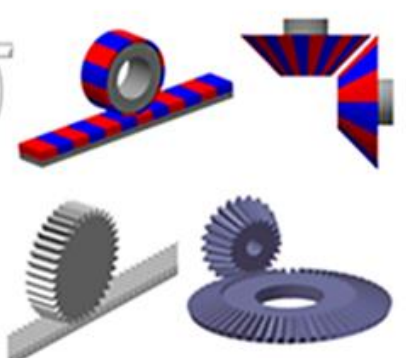

b)

c)

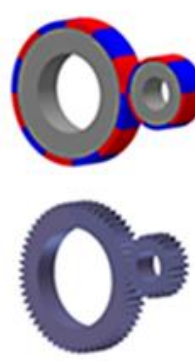

d)

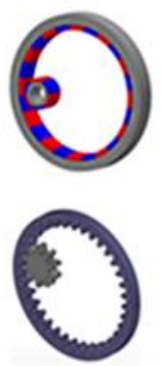

e)

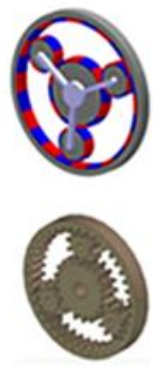

f)

Figure 3 Comparative display of magnetic and mechanical gears:

a) worm gear, b) rack and pinion gear, c) bevel gear, d) external spur gear, e) internal spur gear, f) planetary gear [1]

In addition to these transmissions, there are also gears of more complex shape, such as a magnetic gear with helical teeth, worm gear and magnetic gear with skew shafts. These gears were suggested by Tsurumoto and Kikuchi, and their construction is described in detail in [9, 10, 4]. The hyperboloid gear has also been described in [15], with radial magnetization and hyperboloid north and south pole. The converted magnetic gears also include the magnetic planetary gears and variators. The torque, which is transmitted by a planetary gear, depends on the number of satellites. It can be increased with increasing number of satellites, but then the moment of inertia increases as well. The good side of these gears is that they have a high transmission ratio, high torque density, and three modes. The bad side of these gears is that the complexity of the gear structure increases with the increase of the number of satellites. The development of magnetic planetary gear is described with more details in $[16,17]$, also the gear analysis has been performed, and their application in devices with variable inertia has been described in [18].

Field-modulated magnetic gears are also called flux guided magnetic gears. With previously described type of the gears, the gears have a very short distance, so that the magnetic flux travels from one gear, through the air, to the second gear. Unlike them, there is a part made of iron, in field-modulated magnetic gears, which leads the flux from one gear to another. There are a large number of patents of the field-modulated magnetic gears. The principle of their work is based on the use of ferromagnetic materials for magnetic field modulation. These gears mainly consist of two rotors and the modulator. These gears include: linear concentric magnetic gear, axial magnetic gear and coaxial magnetic gear [1].

Linear magnetic gear is described in $[19,20]$ and it is shown in Figure 4 a). It has a tubular shape and its working principle is based on the change of the magnetic field produced by two movers with permanent magnets. The ferromagnetic parts, used for modulation of the magnetic field, are placed among them.

Axial magnetic gear is proposed in [21], and one of the gears of this type is shown in Figure $4 \mathrm{~b}$ ). This gear concept is used when isolation between input and output shaft is necessary. Most often the mover of lower speed is made of silicon steel strip.

Coaxial magnet gear (CMG) is shown in Figure $4 \mathrm{c})$. It consists of the outer and inner rotor, and the modulator, which is situated between them. Modulator is composed of a cage, on which there are parts of a ferromagnetic material. Ferromagnetic material provides modulation (changing) of the magnetic field. This concept of transmission is patented by 
Martin [22], however, its performances, especially high magnetic density, are more discussed in the papers $[23,24]$. The inner rotor is usually the rotor of the higher speed rotation, and outer rotor is the rotor of the lower speed rotation.

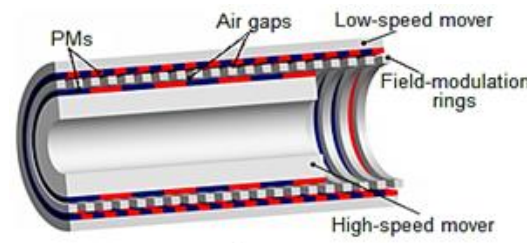

a)

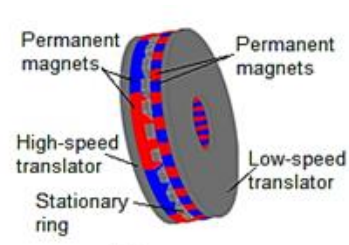

b)

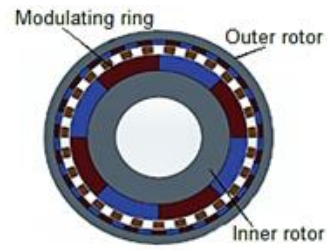

c)

Figure 4 Field-modulated magnetic gears a) Linear magnetic gear [25], b) Axial magnetic gear [21], c) Coaxial magnetic gear $(C M G)$ [23]

Comparative characteristics of mechanical and magnetic gears are given in Table 1. Some of the advantages of magnetic gears are that there are no noise and vibrations, no contact, so therefore, there is no need to use a lubricant. In certain case, the magnetic gears can transmit higher torques than the mechanical gear transmissions. In some concepts, the magnetic transmissions can be physically separated, so that, for example, they can be used in the food and chemical industries. At the overload of these gears, they would not be damaged, but it would come to gear slipping.

Table 1 Gear ratios and densities of torque for mechanical and magnetic gears [23]

\begin{tabular}{|c|c|c|}
\hline Gear type & Transmission rate & Torque density $\left[\mathrm{kNm} / \mathrm{m}^{3}\right]$ \\
\hline Mechanical spur gear & $1.4-28000$ & $100-200$ \\
\hline $\begin{array}{c}\text { Multielement } \\
\text { MG }\end{array}$ & $24: 1$ & 3.96 \\
\hline $\begin{array}{c}\text { Involute } \\
\text { MG }\end{array}$ & $3: 1$ & 1.7 \\
\hline Magnetic worm gear & $33: 1$ & 0.74 \\
\hline Magnetic skew gear & $1.7: 1$ & 0.15 \\
\hline $\begin{array}{c}\text { Parallel-axis } \\
\text { MG }\end{array}$ & $4: 1$ & 11.6 \\
\hline Perpendicular-axis & $1: 1$ & 3 \\
\hline Magnetic torque coupler & $1: 1$ & 91.9 \\
\hline MPG & $3: 1$ & 97.3 \\
\hline
\end{tabular}




\section{APPLICATION OF MAGNETIC GEARS}

Since nowadays, the goal is to minimize environmental pollution and use the renewable energy sources, the interest for magnetic gears increases. These gears are not lubricated, there is no risk of lubricant pouring out into eg. the water. This is a very good side of these gears, especially in terms of environmental protection.

Linear, planetary, and even coaxial magnetic gears can be used in hybrid vehicles $[11,12,13]$. Figure 5 presents the model of a linear gear used in vehicles [23].

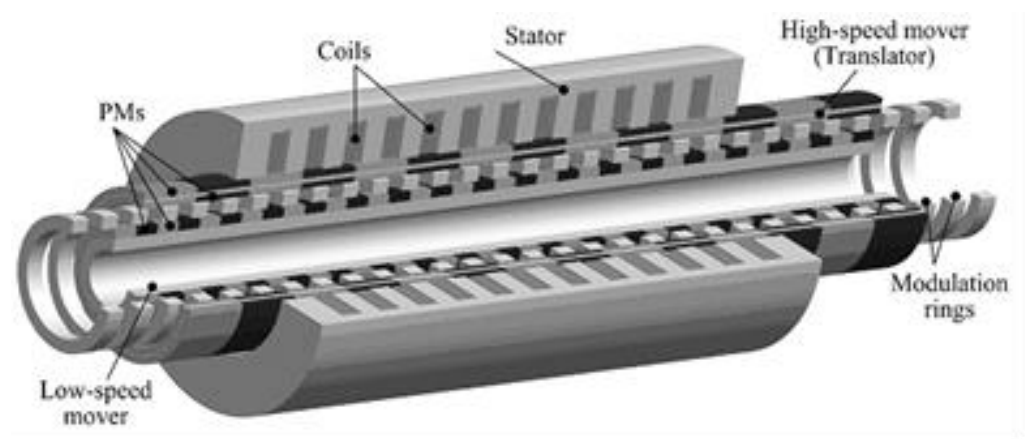

Figure 5 Linear magnetic gear in vehicles [12]

The company Magnomatics has managed to combine the magnetic gears with stator windings, thus getting Pseudo Direct Drive (PDD). PDD represents the replacement of motor and reducer and it can be used in all cases where conventional motor and reducer are used. One PDD is shown in Figure 6 [14].

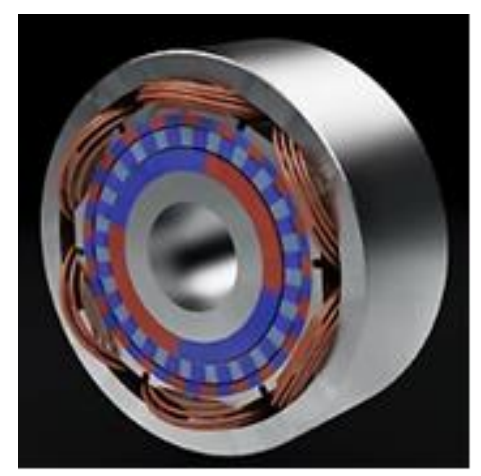

Figure 6 Pseudo Direct Drive (PDD) [14]

PDD may be applied in oil and gas industries, aeronautics (Figure 7 a)), as well as in maritime industry (Figure 7 b)) [14]. 


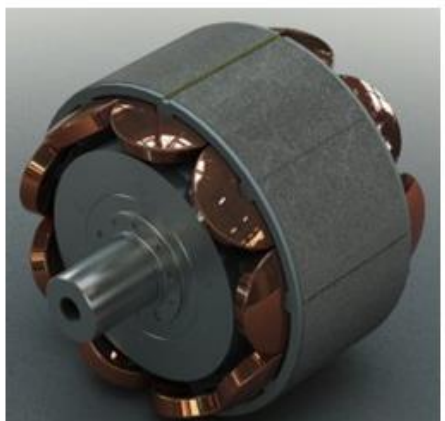

a)

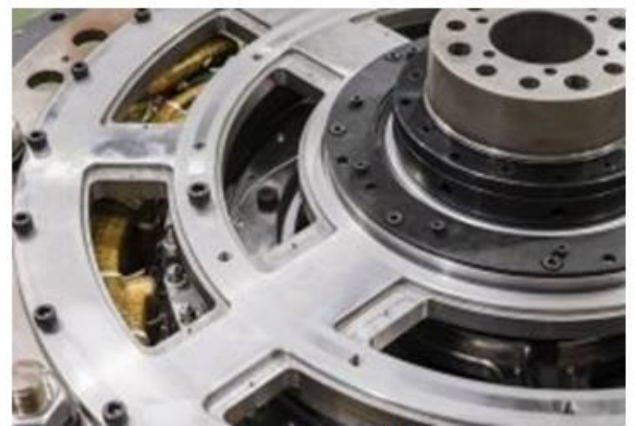

b)

Figure 7 a) PDD used in aerospace, b) PDD used in marine propulsion [14]

The Magnomatics Company has developed MAGSPLIT for hybrid vehicles (Figure 8), used for speed variation, which is a substitute for conventional ECVT systems for hybrid vehicles [14].

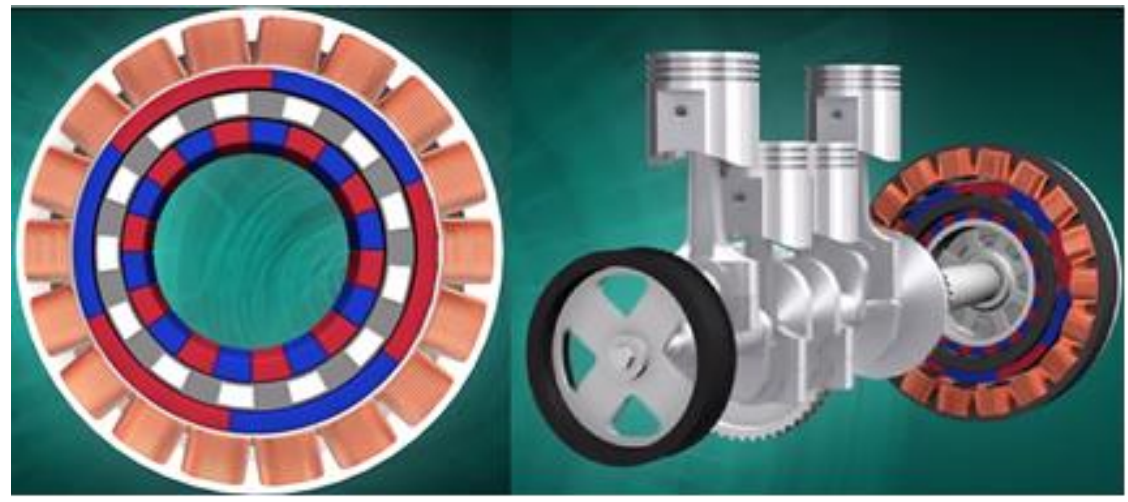

Figure 8 MAGSPLIT [14]

Linni Jian in [26] has given the design and analysis of magnetic motor for electric vehicles. A Halbach array of permanent magnets was used in magnetic gear of this motor. The appearance of the gear and the motor, built into the wheel of the vehicle, is shown in Figure 9. 

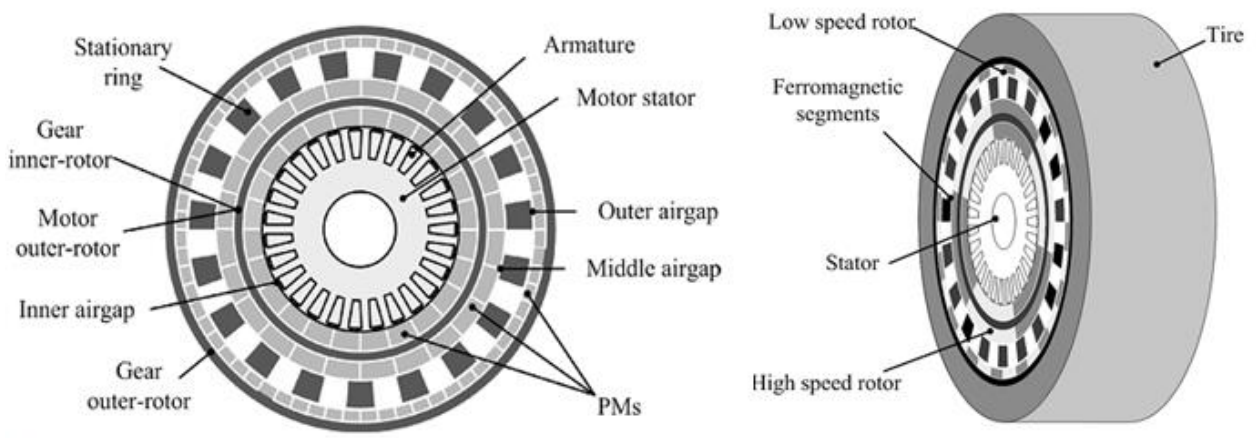

Figure 9 Halbach magnetic geared permanent magnet Motor [26]

The Ricardo Company has patented its mechanism with magnetic gears and magnetic couplings, as it is shown in Figure 10 a). This company has also developed Kinergy flywheel system, which is very compact, and it is shown in Figure 10 b). Flywheels are particularly good for vehicles which often brake, such as, cars, trucks, trains, trams, buses, machines for material handling, such as cranes and elevators, and even vans for delivery [27].

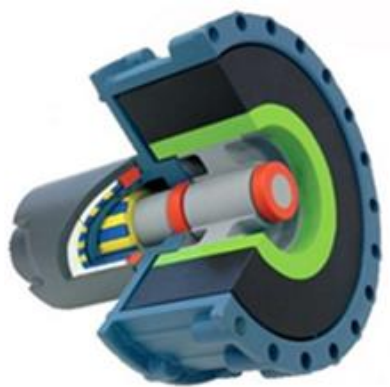

a)

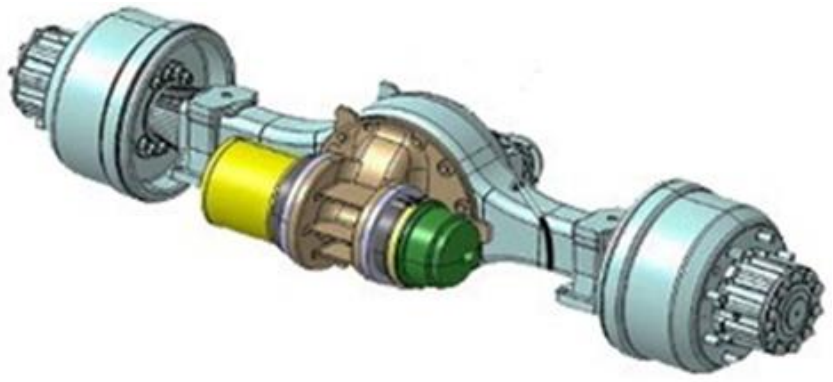

b)

Figure 10 a) Ricardo's flywheel, b) Kinergy flywheel system integrated into a rear axle assembly [27]

Figure 11 a) shows the high efficiency excavator (HFX), where the new type of the flywheel, by the Ricardo Company with the name Ricardo TorqStor, is applied (Figure 11 b)). 


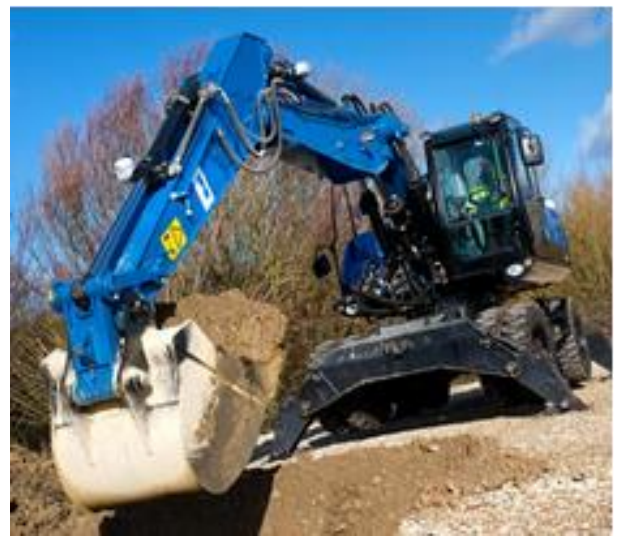

a)

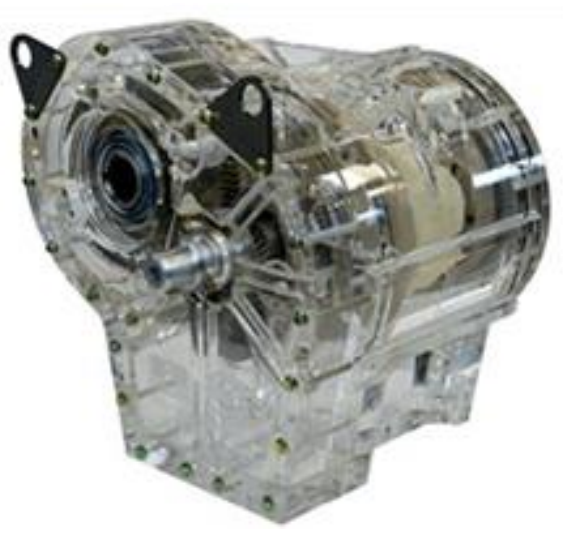

b)

Figure 11 a) High Efficiency Excavator, b) TorqStor [28]

The Ricardo Company, in cooperation with companies Torotrak, Optare, and Allison, developed Flybus Project that proved to be very good, because by using the flywheel while driving the bus, the emission of harmful gases decreases, fuel costs are reduced, as well as the brake wear [28]. Application of the flywheel within Flybus Project is shown in Figure 12.
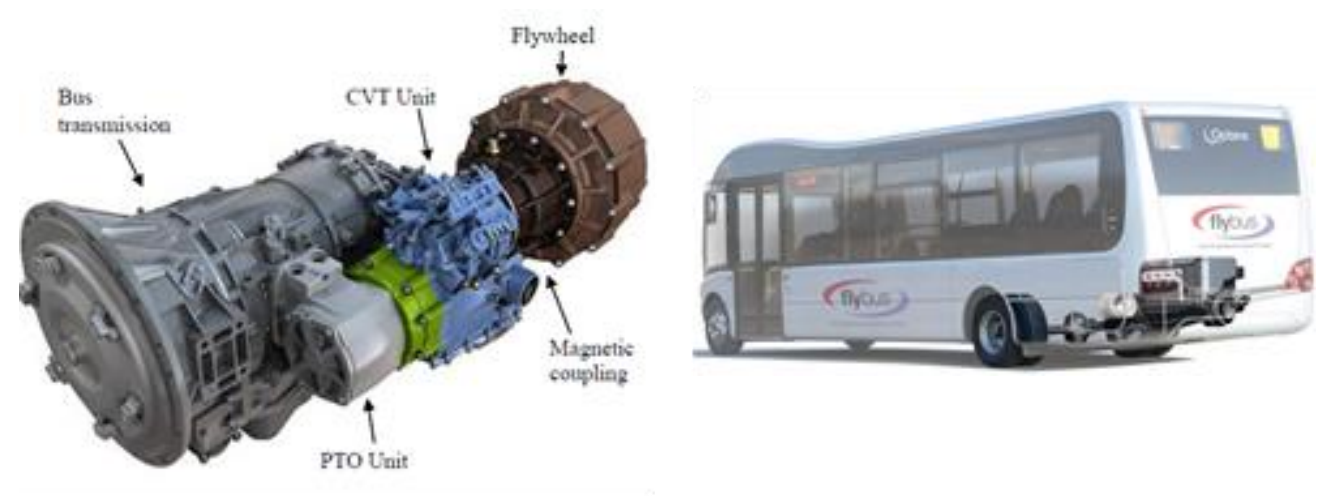

Figure 12 Application of flywheel in Flybus project [28]

Flybrid was developed within the Torotrak Groups and in cooperation with Ricardo Company (Figure 13 a)). The Flybird was developed for use in Formula 1. In June 2011, the new Clutched Flywheel Transmission (CFT) based system raced in the Le Mans 24-hour race and thus, had driven the first hybrid car that competed in this race. CFT is suitable for passenger cars as well. Figure $13 \mathrm{~b}$ ) shows the use of Flybride flywheel with Jaguar test car [28]. 


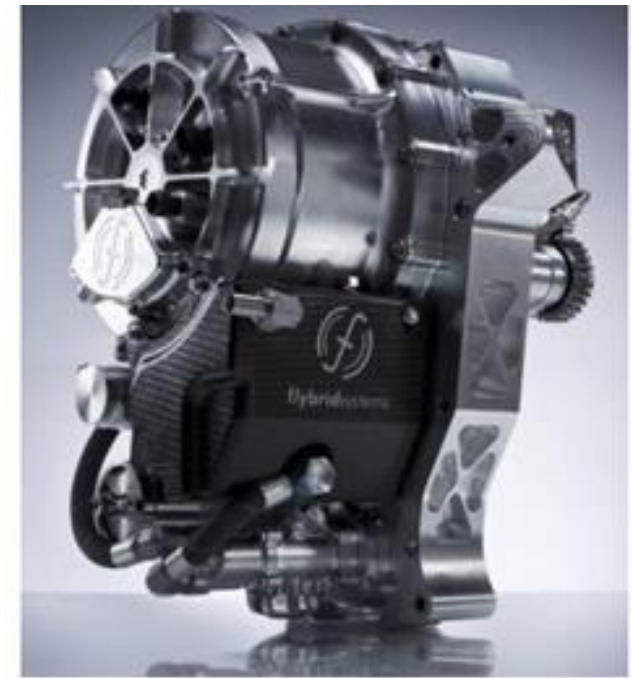

a)

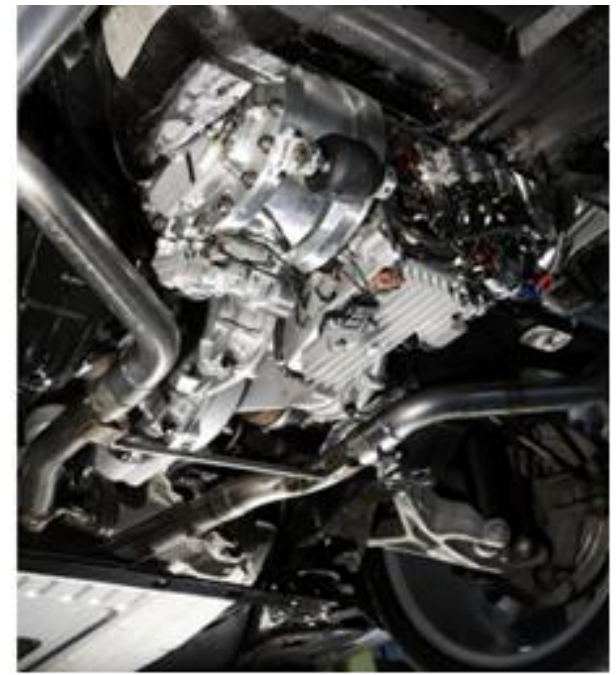

b)

Figure 13 a) Clutched Flywheel Transmission, b) Flybrid flywheel in Jaguar test car [28]

Ricardo, Artemis Intelligent Power and Bombardier Transportation under the DDFlyTrain project examined the impact of using high speed flywheel energy storage technology on DMU (Diesel Multiple Unit) trains. The hybrid solution of this project is based on the use of high efficiency Artemis Digital Displacement hydraulic pump-motor transmission and Ricardo's TorqStor high-speed flywheel energy storage technology. Figure 14 shows TorqStor high-speed flywheel used in DDFlyTrain Project.
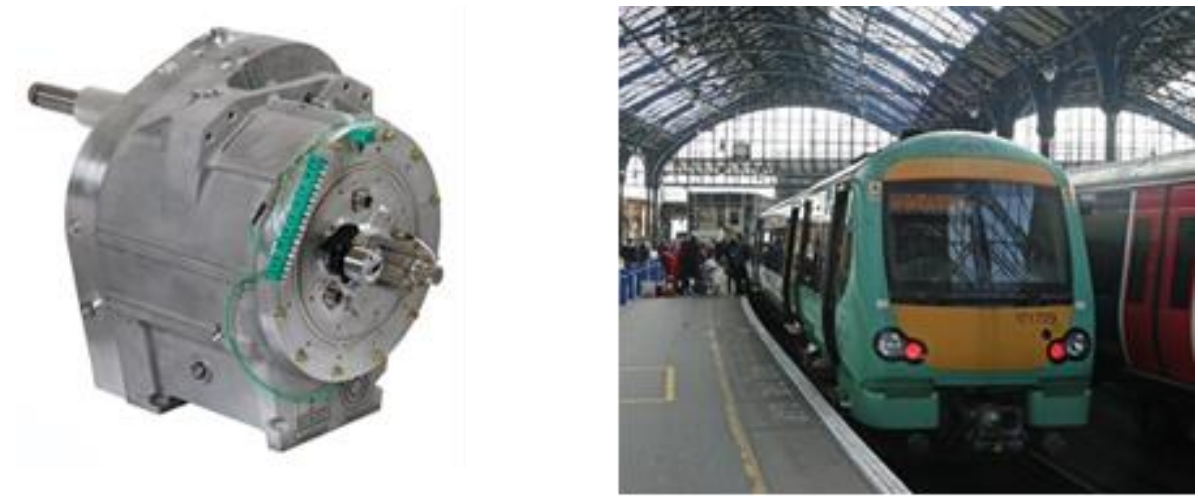

Figure 14 Flywheel used in DDFlyTrain project [28]

General Motors has applied the permanent magnet motor in its model Chevrolet Spark EV, as shown in Figure 15. 


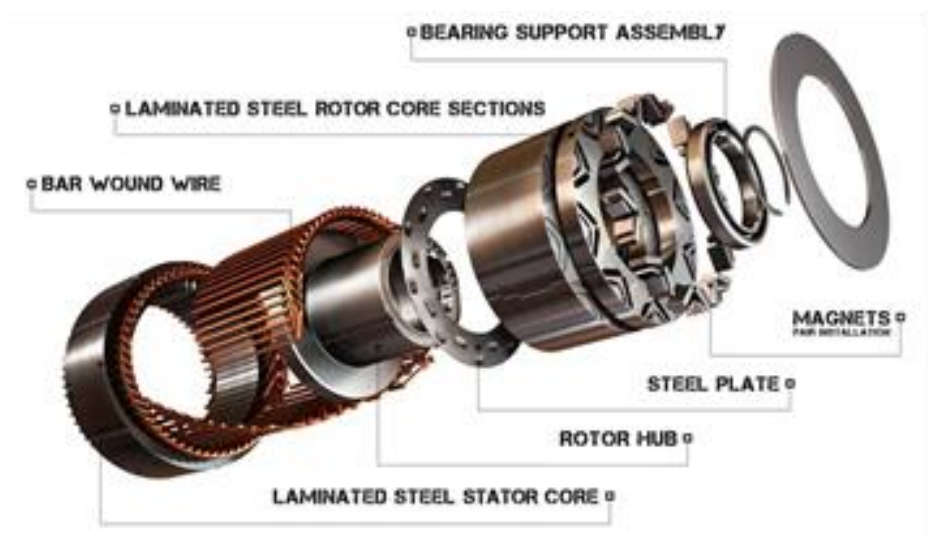

Figure 15 GM's permanent magnet EV motor [29]

In [30], a mechanical planetary gear of hybrid vehicles is replaced with magnetic planetary gear. The solution of such a magnetic planetary gear is given in Figure 16, where the generator, marked the MG1 and MG2, is a permanent magnet synchronous machine.

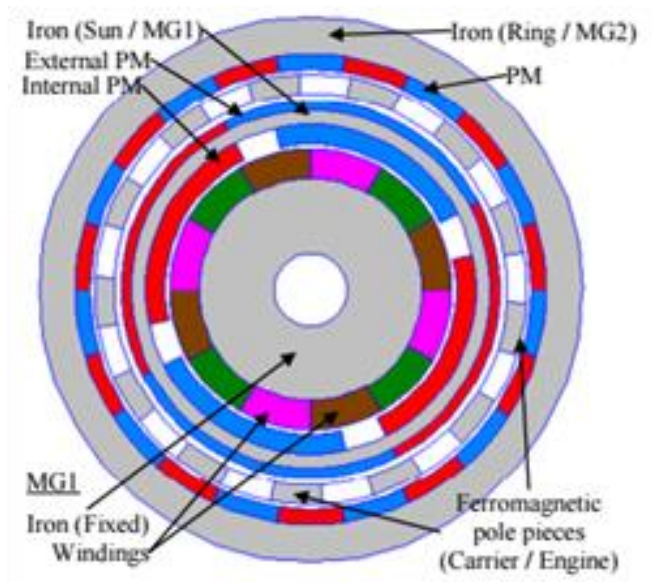

Figure 16 Magnetic planetary gear in hybrid vehicles [30]

The use of magnets in motors is given in [31]. Permanent magnet starter (PMGRpermanent magnet gear reduction starter) is a smaller in size, of simpler construction and it is less heated compared to conventional starters. Such a starter is shown in Figure 17. The magnetic starter uses 4 or 6 pairs of magnets instead of coils. 


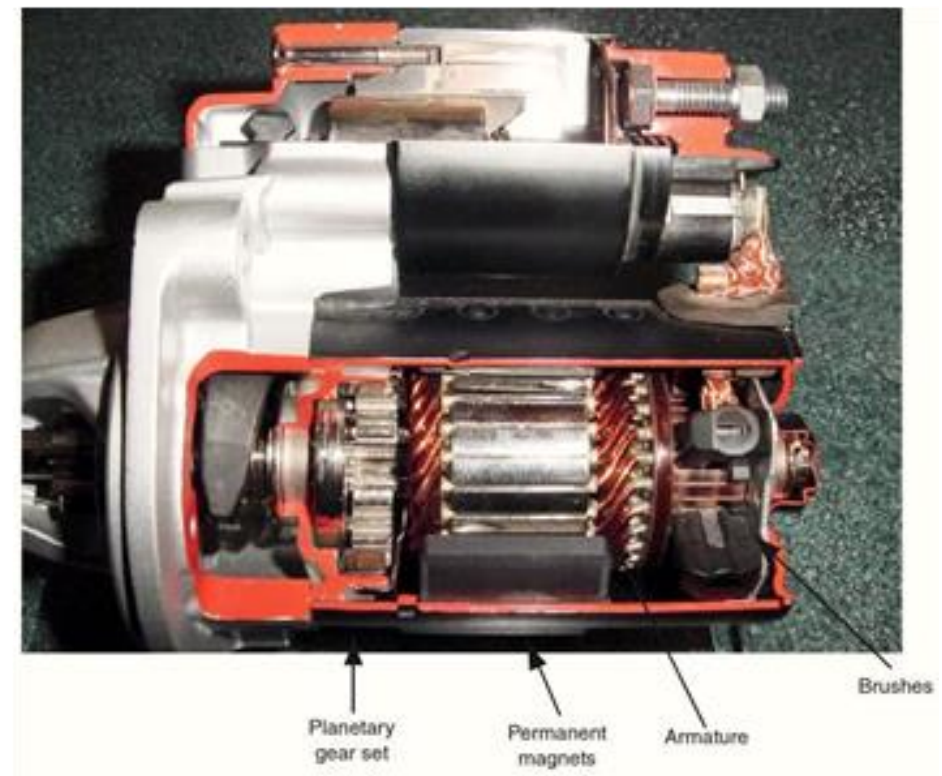

Figure 17 PMGR starter [31]

Magnetic transmissions are also used in spacecraft. One such prototype is shown in Figure 18 [32].

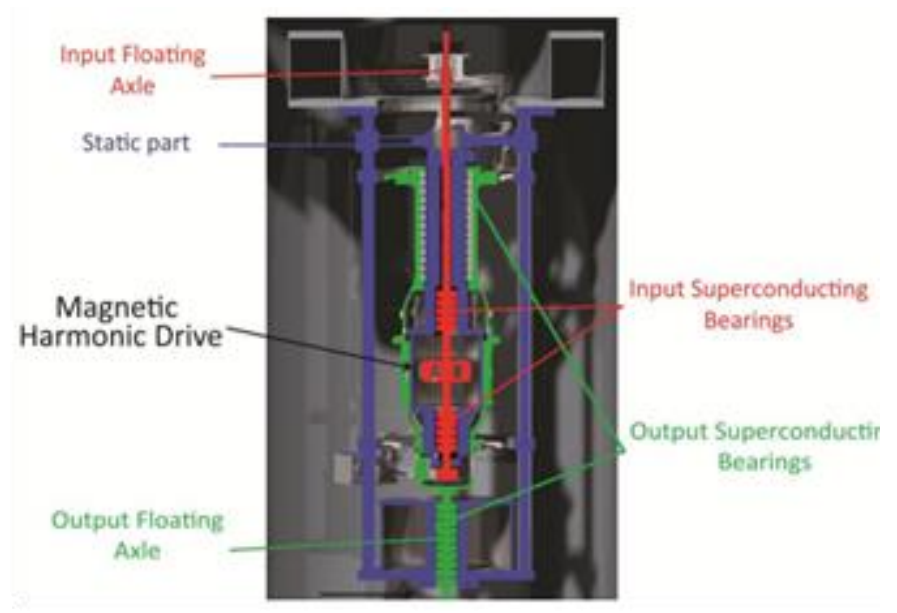

Figure 18 Magnetic transmission in aerospace [13]

A newer type of magnetic gears is magnetic cyclo gears. These gears, so far, are in the testing phase. The testing of the gears for use in hybrid vehicles is performed in $[18,32$, 33].

These are just some of the examples of application of magnetic gears with means of transport. In the future, this application will be even greater, both in vehicles and in industry in general. 


\section{CONCLUSIONS}

Nowadays, when the environmental pollution is the global problem, the aim is to find technologies whose use would reduce environmental pollution, so that the magnetic gears become significant in that way. The most importance is given to the use of magnetic gears in vehicles and means of transport. By combining magnetic gear with stator with electrical windings, the Magnomatics Company has thereby obtained Pseudo Direct Drive (PDD), which is the replacement of the motor and reducer and it can be used wherever the conventional motor and reducer are used. Flywheels in combination with magnetic gears are a new way to reduce fuel consumption in vehicles. The thing that with magnetic gears there are less or even no damage, that they do not create the noise and that they do not need to be lubricated, goes in favour of more frequent use of these gears. Considering that this is a new type of gears, it can be assumed that these advantages will affect, in the future, the more increasing use of magnetic gears. Most, if not all, kitchen appliances will have these gears, each hot drink in a cafe or a dish prepared at home will be obtained with the help of magnetic gears. Buses, trains, light and heavy trucks, taxis and private cars will move with the help of magnetic gears. All this will help to preserve the environment and improve the quality of life.

\section{ACKNOWLEDGMENT}

This paper presents the research results obtained within the framework of the projects TR-35021 and TR-35033 financially supported by the Ministry of Education, Science and Technological Development of the Republic of Serbia.

\section{REFERENCES}

[1] Agošton, D.: "Analysis of microclimate conditions in motor vehicle cabin in transient conditions", master thesis, 2014, University of Novi Sad, Faculty of Technical Sciences.

[2] Montague R. G.: Control of drive trains incorporating magnetic gears, Ph.D. Thesis, Department of Electronic and Electrical Engineering, 2011.

[3] Armstrong C. G.: Power transmitting device, US Pat. 687292, 1901.

[4] Jørgensen F. T.: Design and construction of permanent magnetic gears, Aalborg Universitet, 2010.

[5] Neuland A. H.: Apparatus for transmitting power, U.S. Patent 1171 351, 1916.

[6] Ackermann B.: Magnetic drive arrangement, US Pat. 5994 809, 1999.

[7] Hetzel M.: Low friction miniature gear drive for transmitting small forces, and method od making same, US Pat. 3792 578, 1974.

[8] Mabe W. J.: Magnetic transmission, US Pat. 5013 949, 1991.

[9] Kikuchi, S., Tsurumoto K.: Design and characteristics of a new magnetic worm gear using permanent magnet, IEEE Transactions on Magnetics, Vol. 29, No. 6, pp. 29232925, 1993.

[10] Yao, Y. D., Huang D. R., Hsieh C. C., Chiang D. Y., Wang S. J., Ying T. F.: The radial magnetic coupling studies of perpendicular magnetic gears, IEEE Transactions on Magnetics, Vol. 32, No. 5, pp. 5061-5063, 1996.

[11] Jian L., Chau K. T., Jiang J. Z.: An integrated magnetic-geared permanent magnet inwheel motor drive for electric vehicles, IEEE Vehicle Power and Propulsion Conference (VPPC), Harbin, China, September 3-5, 2008. 
[12] Li W., Chau K. T.: A Linear Magnetic-geared Free-piston Generator for Rangeextended Electric Vehicles, Journal of Asian Electric Vehicles, Vol. 8, No. 1, pp. 1345-1349, 2010.

[13] Perez-Diaz J. L., Diez-Jimenez E., Valiente-Blanco I., Cristache C., AlvarezValenzuela M-A., Sanchez-Garcia-Casarrubios J., Ferdeghini C., Canepa F., Hornig W., Carbone G., Plechacek J., Amorim A., Frederico T., Gordo P., Abreu J., Sanz V., Ruiz-Navas E-M., Martinez-Rojas J-A.: Performance of Magnetic-Superconductor Non-Contact Harmonic Drive for Cryogenic Space Applications, Journal Machines, Vol. 3,No. 3, pp. 138-156, 2015.

[14] http://www.magnomatics.com, received 25.05.2016.

[15] Tsurumoto K. and Kikuchi S., A new magnetic gear using permanent magnet, IEEE Transactions on Magnetics, Vol. 23, No. 5, pp. 3622-3624, 1987.

[16] Kyung H. H., Young J. O., Jung P. H.: Design and characteristic analysis of noncontact magnet gear for conveyor by using permanent magnet, Industry Applications Conference, 37th IAS Annual Meeting, Conference Record of the, Vol. 3, pp. 1922- 1927, 2002.

[17] Huang C. C., Tsai M. C., Dorrell D. G., Lin and B. J.: Development of a magnetic planetary gearbox, IEEE Transactions on Magnetics, Vol. 44, No. 3, pp. 403-412, 2008.

[18] Kong F., Ge Y., Zhu X.: Optimizing design of magnetic planetary gearbox for reduction of cogging torque, IEEE Vehicle Power \& Prop. Conf. (VPPC), 15-18 Oct. 2013.

[19] Atallah, K., J. Wang, and Howe D.: A high-performance linear magnetic gear, Journal of Applied Physics, Vol. 97, No. 10, 10N516-10N516-3, 2005.

[20] Rens, J., Atallah, K., Calverley S. D., Howe D.: A novel magnetic harmonic gear, IEEE Transactions on Industry Applications, Vol. 46, No. 1, pp. 206-212, 2010.

[21] Mezani S., Atallah, K., Howe D.: A high-performance axial-field magnetic gear, Journal of Applied Physics, Vol. 99, No. 8, 08R303-08R303-3, 2006.

[22] Martin T. B.: Magnetic transmission, US Pat. 3 378710, 1968.

[23] Li X., Chau K.-T., Cheng M., Hua W.: Comparison of magnetic-geared permanent magnet machines, Progress In Electromagnetics Research, Vol. 133, pp. 177-198, 2013.

[24] Tomoyuki F., Yoshinori A., Kosuke N., Masaru O., Takashi T., Masato E., Kazunobu S.: Surface Magnet Gears with a New Magnet Arrangement and Optimal Shape of Stationary Pole Pieces, Journal of Electromagnetic Analysis and Applications, Vol. 5, pp. 243-249, 2013.

[25] Li W. and Chau K. T.: Analytical field calculation for linear tubular magnetic gears using equivalent anisotropic magnetic permeability, Progress In Electromagnetics Research, Vol. 127, 155-171, 2012.

[26] Jian L., Chau K. T.: Design and Analysis of an Integrated Halbach-magnetic-geared Permanent-magnet Motor for Electric Vehicles, Journal of Asian Electric Vehicles, Vol. 7, No. 1, 2009.

[27] Crosse J.: The science of spin: flywheels, Designfax weekly eMagazine, Vol. 09, No. $17,2013$.

[28] http://www.ricardo.com/en-GB/News--Media/Press-releases/, received 28.05.2016.

[29] http://www.gizmag.com/gm-85-kw-ev-motor/20329/, received 29.05.2016.

[30] Baghi L., Gouda E., Mezani S., Rezzoug A.: Hybrid vehicle with a magnetic planetary gear, EFEEA'10, International Symposium on Environment Friendly Energies in Electrical Applications, Ghardaïa, Algeria, November 2-4, 2010. 
[31] Hollembeak B.: Today's Technician: Automotive Electricity and Electronics, 6th edition, Cengage Learning, 2015.

[32] Jørgensen F. T., Andersen, T. O. and Rasmussen, P. O.: The Cycloid Permanent Magnetic Gear, IEEE Transactions on Industry Applications, Vol. 44, No. 6, pp. 16591665, 2008.

[33] Mahesh N. G., Gupta A. P.,: The Design of Power Transmission system through The Cycloid Magnetic Gear for Hybrid Vehicles, 14th National Conference on Machines and Mechanisms NIT, Durgapur, India, pp. 468-470, 2009. 
Intentionally blank 